\title{
Examining Consumer Behaviour in the UK Energy Sector through the Sentimental and Thematic Analysis of Tweets
}

Short title for the paper

\section{Examining Consumer Behaviour in the UK Energy Sector}

Authors

Emmanuel Mogaji (Corresponding Author)

Room QA248, Department of Marketing, Events and Tourism,

University of Greenwich,

Park Row, Greenwich, London, SE10 9LS.

e.o.mogaji@greenwich.ac.uk

+44(0)2083317990

Janarthanan Balakrishnan

Thiagarajar School of Management

Pamban Swamy Nagar, Madurai District,

Thiruparankundram, Tamil Nadu 625015, India

reachjanarthanan@gmail.com

+919787746413

Tai Anh Kieu

Department of Research Administration - International Relations, University of Economics and Finance,

Ho Chi Minh City, Vietnam

kieuanhtai@gmail.com

\section{Authors' Bio}

Emmanuel Mogaji holds a $\mathrm{PhD}$ in Marketing, and he is a Lecturer at the University of Greenwich, Fellow of the Higher Education Academy (HEA) and a Certified Management \& Business Educator (CMBE). His present area of interest for research includes attitude towards brands, consumer behaviours on social media and sentiment analysis. He has published peerreviewed journal articles and book chapters and presented his works in a large number of national and international conferences.

Janarthanan Balakrishnan completed his $\mathrm{PhD}$ from National Institute of Technology, Tiruchirapalli, India. His thesis "Indian consumers' perception towards social media advertisements" received sound applause at various presentations. His present area of interest for research includes cyberpsychology, consumer behaviour, marketing communication, social media marketing, and entrepreneurship. So far, he has published his works with more than 15 international journals of high repute.

Tai Anh Kieu completed his PhD with focus on Consumer-Brand Relationships from Western Sydney University. He has Over 20 years of advertising and marketing experience, working on various international brands and campaigns. Having worked with both agency and client sides. Highly adaptable to diverse working environment. Result-oriented. A brand building enthusiast. 


\section{Examining Consumer Behaviour in the UK Energy Sector Through the Sentimental and Thematic Analysis of Tweets}

Consumer engagement with brands on social media has been empirically proven. However, little is known about consumers' natural behaviour on social media, as literature on this topic is still in an early stage of its evolution. Accordingly, this study aims to investigate and understand the group interactions of consumer behaviour, with a specific focus on tweets within the UK energy sector. Energy is a significant utility in the UK, and the sector is evolving more rapidly than ever before, with pressure being applied to energy suppliers to meet the demands of consumers. This study draws on social capital theory to investigate how UK consumers engage with their suppliers, as well as the knowledge-sharing capabilities of the Twitter community. In Study 1, Python was used to conduct tweet mining and sentiment analysis to investigate the polarity in consumer engagement with 82 energy companies in the UK. Results indicated overall positive sentiments towards the energy suppliers, although the level of engagement varies across the different groups of suppliers. Study 2 followed up with a qualitative insight into the factors shaping consumers' behaviour as they engage with brands on social media. A thematic model emerges in the form of an interrelated conceptual theory comprising three stakeholders, the key relationships between them, and their natural behaviours. This study offers a contemporary, essential, and interconnected understanding of consumer behaviour online with a focus on the energy sector, and further advances research into online consumer behaviour, sentiment analysis, netnography and social media research.

Keywords: Consumer Behaviour; Energy Suppliers; Sentiment Analysis; Thematic Analysis; Twitter. 


\section{INTRODUCTION}

Consumer engagement with brands on social media has been empirically proven. Social media offers an important avenue for consumers to interact with brands (Tsai \& Men, 2013), along with the opportunity for brands to ascertain consumers' perceptions of them and their competitors (Mogaji \& Farinloye, 2017). Like any other media source, social media has become an important communication platform allowing consumers to explicitly connect with brands (Chu, 2011) and has had a substantial impact on shaping consumer behaviour (Kapoor, et al., 2018).

Consumer behaviour on social media is dynamic, robust, and heterogenic (Dwivedi, et al., 2015; Shareef, et al., 2016) and is a growing strand of research that requires thorough exploration, as brands are keen to improve their service quality and understand human behaviours. While social media is often used to promote products and build brand communities (Hayes \& King, 2014; Shareef, et al., 2016), it is seldom used to understand consumer behaviour. Moreover, although some studies have explored consumer behaviour in other sectors, the energy sector literature is still in its early stages. Indeed, a study by Mogaji et al. (2018) that analysed user-generated content posted on the Facebook pages of UK energy companies is one of the few studies to have used social media to understand consumer behaviour in the energy sector.

Energy is a crucial utility that is often provided in the forms of gas and electricity to power homes and businesses. The energy sector is evolving more rapidly than ever before, and there is pressure on energy suppliers (ES) to meet consumers' demands (Coyne, 2017). The lack of trust and competition in the industry, as well as concerns about climate change and environment-friendly energy sources, present challenges for ES and highlight the need for them to understand their consumers, especially in the social media domain. Since social media has 
become a knowledge bank and an expressive domain for consumers to share their thoughts and feedback, it is important to understand consumer sentiments and behaviour towards the UK energy sector.

This study therefore aims to address the following two research questions:

1. What are consumers' sentiments regarding UK ES?

2. What are the behaviours of UK energy consumers on social media?

In particular, this study focuses on exploring consumer behaviour on Twitter in relation to UK ES. Following a similar methodological approach to that adopted by Mogaji and Erkan (2019), who explored consumer experiences with the transportation sector through social media, this study investigates how UK consumers engage with their ES and make use of the knowledgesharing capabilities of the Twitter community. Sentiment and thematic analyses were carried out to operationalise the social ties and shared goals with the social network on Twitter. Three key relationships involving consumers and brands were revealed, and the behaviour inherent in these relationships was also examined.

\section{LITERATURE REVIEW}

\section{Social media and consumer behaviour}

Research into consumer behaviour on social media tends to look at how social media marketers create diverse content with the aim of attracting consumers, or attempt to understand usergenerated brand mentions on social media (Goh, et al., 2013; Susarla, et al., 2012). Social media has become a powerful tool for understanding brand strength among internet users (Bruhn, et al., 2012), while previous research has indicated that user-generated content (UGC) on social media can impact brand equity (Andéhn, et al., 2014; Balakrishnan \& Manickavasagam, 2016; Schivinski \& Dabrowski, 2015). 
Each social media platform has created its own identity in terms of what it can offer its users. For example, Twitter is an interactive microblogging social media platform that builds engagement via short message dissemination (Walker et al., 2017; Natarajan, et al., 2014). Twitter differs from other social media domains in multiple ways: namely, its ability to facilitate real-time conversation, its precise format, its customer service and its popularity in engagement (Parmar, 2015; Ibrahim et al., 2017). Consumers can share both positive and negative sentiments in virtual groups on Twitter, and both active and passive users are able to view this information (Stieglitz \& Dang-Xuan, 2013). Moreover, various deep learning algorithms have now emerged that use natural language processing to help marketing analytics understand the meanings inherent in UGC. It is also crucial to understand how UGC has evolved through the lens of consumer behaviour theories (Balakrishnan \& Griffiths, 2017). Among the social media platforms where UGC can be garnered, Twitter appears to be a definitive consumer engagement tool. It gives consumers the freedom to express their diverse views, as compared to another popular social networking site, Facebook, on which conversation is more controlled (Mueller, 2018).

Due to Twitter's ability to attract and retain public attention (Walasek et al., 2018) and its spontaneous nature (Valos et al., 2017), it has evolved into one of the most formidable tools for use by brands to engage with consumers and to evaluate their brand's strength (Ghiassi, et al., 2013). One unique characteristic of Twitter when compared with other social media platforms is its short text format, which requires users to express their thoughts in a clear and concise manner. Unlike emotions expressed in other textual forms, the character limitation and real-time conversation result in not only new forms but also far more emotional statements (Roberts, et al., 2012). Consumers use Twitter to express both positive and negative sentiments and emotions. Bae and Lee (2012) examined the valence of popular tweets and confirmed that twitter audiences have expressed both positive and negative sentiments. Philander and Zhong 
(2016) confirmed the same with customers in the context of the hospitality industry. In one study, Makarem and Jae (2016) classified high-, moderate-, and low-intensity levels of emotion that consumers take to Twitter when boycotting brands. There are also some studies supporting the idea that tweets can be decoded to understand the emotions and sentiments of the users (Bermingham and Smeaton, 2010; Thelwall et al., 2011). Further research has been emerging, with attempts to decode different emotions and sentiments posted as tweets (Roberts, et al., 2012).

Furthermore, the growth of social media content has also improved consumer empowerment in terms of providing vast amounts of information (Xiang \& Gretzel, 2010). For example, the literature has shown that brands use Twitter as a customer relationship portal (Heller Baird \& Parasnis, 2011). Dissecting the information in tweets and understanding how brand mentions play a role in shaping brand image requires more precise examination. Unlike traditional media, Twitter shares both authentic and inauthentic information regarding brands, which the brands must engage with and effectively manage. Marwick and Boyd (2011) explain that the authenticity of the message rests on the individual who tweets; as such, it is possible to evaluate this authenticity based on the value the message delivers and the individual who posted it (Marwick and Boyd, 2011). However, it can also be difficult for some consumers to recognise when information is correct.

Consumer relationship and engagement has become an integral term in social media usage (Heller Baird \& Parasnis, 2011). Marketers adopt various approaches in an attempt to build sustainable positive relationships with consumers through social media platforms. However, creating engagement on social media may not necessarily result in positive comments; in fact, it may actually result in consumers making negative comments about companies (Einwiller \& Steilen, 2015). It is therefore crucial that marketers understand consumer emotions. Building and managing positive UGC in online environments is an important yet challenging task for 
marketers, as the conversations on and contents of social media have become social capital for organisations (Lovejoy \& Saxton, 2012).

Furthermore, most existing research on consumer behaviour in social media environments adopts the 'uses and gratifications' framework (Katz, et al., 1973) to examine consumers' selfgoal-driven behaviour when contributing brand-related content, with little attention being paid to pre-existing consumer-brand relationships or social ties within the social network (Pentina, et al., 2018). To date, no studies have made an attempt to understand consumers' natural behaviour in relation to the social ties within social environments such as Twitter. It is also obvious that an individual's participation in knowledge-sharing in a social network may also be motivated by social capital-related aspects (Chiu, et al., 2006). Thus, this study adopts social capital theory as the theoretical foundation for the mapping of social capital and its relevance

on Twitter. Moreover, this study examines the specific context of the energy sector, a significant utility and rapidly evolving sector in the UK, along with the pressure on energy suppliers to meet the demands of consumers.

\section{The UK energy sector}

The energy industry fuels the UK economy, delivers energy to every corner of the country, and supports industry, business, and homes with a constant and reliable source of power (Energy UK, 2018). The UK energy industry has over 90 members, who produce energy from renewable sources as well as delivering nuclear, gas, and coal energy. The energy industry adds $£ 87$ bn to the British economy and supports one in 49 jobs in the UK (Energy UK, 2018). The Office of Gas and Electricity Markets (Ofgem) supports the Gas and Electricity Markets Authority and is the government regulator for the energy market in the UK. As of June 2018, Ofgem reported that there were 73 active ES in the domestic gas and electricity retail markets. 
The energy industry can be divided into four different groups based on their size and source of energy (Ofgem, 2014; Ofgem, 2019; Farinloye \& Mogaji, 2018). First, there are the 'Big Six' ES (BSES), which is the name collectively given to the six largest energy companies who supply most of Britain's gas and electricity and control the largest market share in Britain's energy sector. Second, there is the large number of independent smaller energy suppliers (ISES), who are well placed to challenge the Big Six's market domination. Third, there are the renewable energy suppliers (RES), who supply only renewable energy. Fourth, there are the so-called 'white label' energy suppliers (WLES), who do not hold a supply licence but instead work in partnership with a licensed 'partner supplier' to offer tariffs under the white label brand.

Due to the existence of these different players, there is competition in the retail market. Ofgem (2018) acknowledged that this market competition between suppliers benefits consumers, noting that it is not surprising that consumers are switching from one provider to another. Indeed, the number of switches between providers in the domestic context in the 12 months leading up to the end of September 2018 was $6 \%$ higher than in the 12 months leading up to August 2017 for electricity and 13\% higher for gas (Ofgem, 2018). Almost half of these switches involved consumers opting to leave a traditional Big Six firm in favour of smaller providers, as switching to a smaller supplier can reduce annual energy bills by around $£ 300$, especially when moving from a pricey standard variable tariff with a Big Six provider to a cheap fixed-term tariff (Goodman, 2018).

Poor customer service within the sector has also been documented. Mogaji et al. (2018) found that UK energy consumers were not satisfied with their relationships with the providers, further noting that consumers wanted a brand that was on their side, that took an interest in their complaints, and that was willing to help them out. In addition, increasingly difficult trading conditions have been acknowledged as the reason why some energy companies have ceased to 
trade. As of December 2018, eight providers had stopped trading; many of these were ISES (McCormick, 2018).

The government's push for sustainable sources of energy is also a concern for the industry and has implications for consumers. The Climate Change Act 2008 stimulated significant changes in the UK energy market (Energy UK, 2018). A core part of the Clean Growth Strategy is the UK government's commitment to phasing out unabated coal-fired electricity by 2025 (HM Government, 2018). The government is also working hard to reduce the UK's dependence on other fossil fuels, leading energy providers to look for alternative and sustainable forms of energy. In addition, the industry is subject to intense political scrutiny and faces the introduction of a price cap on default tariffs (Ofgem, 2018).

Considering the competition within the retail market, consumers' ability to switch providers, concerns around climate change and environmentally friendly energy sources that may not necessarily be cheaper, many ISES ceasing to trade, and the introduction of a price cap, it can be concluded that energy brands need to evaluate their customer behaviour and understand how they can best meet consumer needs. The consumer-brand relationship is considered vital for brand survival and prosperity, as it leads to brand loyalty and contributes to increased repurchase volume and better acquisition rates (Giovanis, 2016; Sabrina \& Shobeiri, 2016).

\section{THEORETICAL FRAMEWORK}

The social capital theory posits that the social network of an individual's relationships - and the set of resources embedded within it - has a strong impact on that individual's knowledgesharing behaviour (Blau, 2017). Social capital is defined as 'the sum of the actual and potential resources embedded within, available through, and derived from the network of relationships possessed by an individual or social unit' (Nahapiet \& Ghoshal, 1998, p. 243). Accordingly, Nahapiet and Ghoshal (1998) posited three interrelated dimensions of social capital: structural 
(the overall pattern of connections between actors), relational (the kind of personal relationships people have developed with each other through a history of interactions), and cognitive (those resources providing shared representation, interpretations, and systems of meaning among parties). This model was further developed by Hau and Kim (2011), who described the structural dimension as the social ties within the network upon which social trust (relational dimension) grows, while all members within the group share the same goals (cognitive dimension).

Social capital is considered a salient factor in facilitating knowledge-sharing in online communities (Chai \& Kim, 2010). The relevance of users' intentions and behaviour to encouraging group cohesion in the social media context is also recognised (Ngai, et al., 2015). In this vein, social capital theory is arguably more suited to facilitating an understanding of consumer behaviour in the social media environment than a related theory, namely social cognitive theory. Social cognitive theory has been widely used to study computer use and internet behaviour in the information systems literature; nonetheless, it should be noted that it focuses only on social cognition (Chiu, et al., 2006). Chang and Chuang (2011) adopted social capital theory to investigate the factors influencing knowledge-sharing behaviour in a virtual community, while Hau and Kim (2011) examined the factors that drive community users to freely share their innovation-conducive knowledge.

While many previous studies have explored online consumer communities via Facebook or other online forums, few have explored Twitter. The fact that Twitter does not support the idea of community could be the reason behind the dearth of literature on this subject. Accordingly, to fill this knowledge gap, the present study draws on social capital theory to investigate how consumers engage with ES on Twitter, the knowledge-sharing capabilities of the social media community, and the consumer behaviours displayed thereafter. Consumers who go online to engage in social media conversations with brands and other consumers do so not only to seek 
out information or try to solve problems, but also treat the online platform as a place to meet other people and find friendship and a sense of belonging (Andrews, 2002; Chiu, et al., 2006).

Due to Twitter's unique features as a social media platform, along with the fact that it differs notably from other online communities used for brand engagement, certain behaviours unique to Twitter are likely to emerge; however, this area is not well researched. Engagement, in the context of this study, refers to the exchange of tweets between the consumers and the ES. This includes instances when a consumer wants to resolve a case, and engages with the ES by mentioning them in a tweet, and also includes the ES's reply to the concerns that have been raised. Moreover, a consumer tweeting their positive experience with an ES is a form of engagement that is marked by a positive sentiment. The conceptual framework, as illustrated in Figure 1, recognises the inherent insight in tweets exchanged between energy brands and their consumers.

Figure 1 about here

Tweets were extracted for sentiment and thematic analysis in order to gain insight into consumer behaviour. By adopting Hau and Kim's (2011) version of the three interrelated dimensions of social capital, sentiment analysis could provide an insight into the social ties within the network, as well as the level of engagement between brands and consumers. These social ties play an important role in forming a positive attitude and a sense of belonging and attachment to the community (Ukpabi, et al., 2019; Blanchard \& Markus, 2004). This then feeds into the thematic analysis, aimed at qualitatively exploring social trust in information sharing within the network and the shared goals within the group. Sentiment analysis is applied in Study 1 (RQ 1), while the consumers' inherent behaviours are revealed in Study 2 (RQ 2). 


\section{STUDY 1: SENTIMENT ANALYSIS}

\section{Methodology}

Sentiment analysis is described as 'the automatic method to extract and analyse the subjective judgments on different aspects of an item or entity' (Soleymania et al., 2017, p. 5). It is a machine learning process involving the application of natural language processing to the identification of expressions that reflect the authors' opinion-based attitudes towards entities (Li \& Hovy, 2017). In line with previous methodology adopted to investigate train-operating companies in the UK (Mogaji \& Erkan, 2019), customer tweets were collected as a direct reflection of their engagement with brands and other consumers. The computer programming language Python was used for the tweet mining and sentiment analysis; more specifically, Twitterscraper was used for tweet mining, while Textblob was used for the sentiment analysis. TextBlob is a Python (2 and 3) library for processing textual data. It holds an extended documentation of words and can handle almost every opinion mining task efficiently. It is uses natural language processing (NLP) and machine-learning principles to analyse the words in a statement, or in this case a tweet, and decide if the overall tweet is positive or negative (Textblob, 2019; Mogaji \& Erkan, 2019).

Tweets from 82 ES $(\mathrm{BSES}=6$; ISES = 41; RES = 11, WLES = 24) were extracted over a oneyear period between 1 July 2017 and 30 June 2018. The extracted tweets contained the username of the ES main account (or the customer service account, in the case of the BSES). Although Ofgem reported that there were 73 active suppliers in the domestic gas and electricity retail markets as of June 2018, some ES joined the market while others ceased to trade after this period. Overall, 480,187 tweets were extracted from the ES during the one-year period. Only 369,247 of these were used for sentiment analysis, as extracted tweets were pre-processed to remove irrelevant or unrelated tweets that did not provide any sentiment or that may have distracted the analyser from interpreting polarity in the most effective way. This process helped 
to conform normal structures that, in turn, considerably improved the performance of the machine learning algorithms (Saleem, et al., 2014). In addition, tweets made by the ES themselves were also excluded, as these tweets were more likely to be either positive or neutral. Instead, the focus was more on the consumers' experiences and their tweets about the service.

\section{Results}

With 369,247 tweets used for the sentiment analysis, tweets with positive sentiments accounted for $48.5 \%(n=179,261)$ of the sample, while tweets with negative sentiments accounted for $12.5 \%(n=46,263)$, and tweets with neutral sentiments accounted for $39 \%(n=143,723)$. Table 1 provides a breakdown of each of the ES groups, along with the number of tweets relating to them; overall, the results indicate that there is an overall positive sentiment towards ES brands in the UK.

------ Table 1 about here -------

The BSES have the largest number of consumers, and this group accounted for $40.5 \%(\mathrm{n}=$ $149,588)$ of the extracted tweets. This finding offers an insight into how often BSES consumers engage with this group on social media compared to other providers. Within the group, British Gas (@ BritishGasHelp) had the highest number of tweets (17,324 neutral, 20,720 positive, and 7,676 negative), while EDF Energy (@edfenergycs) had the lowest number of tweets $(2,087$ neutral, 3,782 positive, and 1,316 negative).

The RES, comprising 11 providers, accounted for $22.4 \%(\mathrm{n}=82,828)$ of the extracted tweets. This group had a considerably large percentage of positive sentiments, which could indicate how consumers feel about the brands, their source of energy, and the services they provide. The ISES (41 providers) accounted for $25.6 \%(\mathrm{n}=94,338)$ of the extracted tweets, while the WLES (24 providers) accounted for $11.5 \%(\mathrm{n}=42,493)$. The latter group had a larger percentage of neutral tweets, which could indicate consumers' awareness that their energy 
supplier is a white label of another supplier and discourage brand engagement. For example, Peterborough Energy is a partnership between Peterborough City Council and an independent supplier (OVO Energy). It is apparent that positive experiences with this brand are seldom tweeted about, as consumers may not be sure of whom to credit.

Although the level of engagement with the other three groups cannot be compared with the Big Six, consumers still find reasons to engage with the RES brands; nine providers had more than 1,000 tweets from consumers in a year. However, engagement with the ISES and WLES was not as good. Only nine of the 41 ISES providers and two of the 24 WLES providers received more than 1,000 tweets from consumers over the course of the year.

\section{STUDY 2: THEMATIC ANALYSIS}

\section{Methodology}

Study 1 provided an insight into the polarity between the opinions of consumers as they engage with their ES online. However, there was no real indication of what factors were shaping those conversations, as sentiment analysis alone cannot provide an understanding of the consumers' experiences and what caused them to have a positive or negative attitude towards the brands. Therefore, a second study was considered important to provide a qualitative insight into what factors shape consumer behaviour as they engage with brands on social media. While Study 1 provides an overview of sentiments and behaviour, Study 2 provides a more in-depth understanding of the reasons behind such behaviours. This is valuable because improving consumer experience is considered crucial in achieving profitability, particularly in highly competitive environments (Hernon \& Nitecki 2001; Chowdhary \& Prakash 2007).

Study 2 adopts a thematic analysis methodology. All indicators of consumer behaviour while engaging with ES were derived from subsequent analysis of the tweets within a netnographic 
context. Netnography, an extension of ethnography, is a 'form of ethnographic research, adopting the participant-observational approach and taking online interactions as its fieldwork' (Kozinets, 2010, p. 1). The online community is advancing as a research stream for qualitative scientists, and netnography is one of the recommended approaches for exploring the diverse cultural dispositions of online communities and interpreting the results in a descriptive or analytical format (Kozinets, 2015; Kozinets, et al., 2014).

Some of the tweets extracted in Study 1 were selected and used for the thematic analysis. Firstly, ES with few tweets throughout the year (an indication of low consumer engagement) were excluded from the thematic analysis. Moreover, following the Twitter account selection criterion applied by Ruggeri and Samoggia (2018), only tweets from Twitter accounts with a minimum average of 100 tweets, retweets, or replies per year (at least one tweet per week since the account was opened) were considered. One hundred tweets mentioning and engaging with the ES using the @ function were collected in June 2018. In addition, data-screening processes were put in place to inspect the extracted tweets (Mogaji, et al., 2016). Tweets from 30 ES were excluded, as they did not meet the Twitter section criteria; 100 tweets were collected from each of the remaining 52 ES. This was an additional effort to conduct data cleaning and preprocessing before the coding. In total, 5,200 tweets were thematically analysed.

Braun and Clarke (2006) noted that thematic analysis involves choices, which should be made explicit in order to guarantee the validity and reliability of the study; among these are the identification of themes within the data and the 'level' at which themes are to be identified. Themes within the tweets were identified in an inductive/'bottom-up' way, as this means that the themes identified would be strongly linked to the data themselves (Patton, 1990). Inductive analysis involves coding data without trying to fit it into a pre-existing coding frame (Braun and Clarke, 2006). This form of thematic analysis is data-driven. The 100 tweets for each of 
the 52 ES were saved as PDFs and imported into NVivo12, a qualitative thematic analysis tool. The analysis and coding were carried out by the first author.

The data was read multiple times to enable a better understanding of how consumers engage with their ES. Braun and Clarke (2006) suggested that, 'Immersion usually involves 'repeated reading' of the data and reading the data in an active way - searching for meanings, patterns and so on'. Subsequently, data exploration was carried out using the Query command in NVivo12, such that an initial analysis was conducted to determine the kind of words participants use in their tweets and how often they are used.

Codes were generated inductively, as there was no pre-existing coding frame. A short description (often one or two words) was given to each tweet, in order to gather together all references to a specific topic on consumer behaviour and engagement with ES. At this stage of the analysis these codes were fluid, changing and emerging. Codes were redefined, new codes were created, and codes were also merged and split to account for new ideas as the coding progressed.

The next step involved identifying and describing links and relationships between codes. Codes were categorised and themes generated based on the relationships between the codes, the frequency of the codes and the underlying meaning across the codes. The themes were shared with the co-author to review and refine them. During this process, it became more evident that some of these themes were closely related. Initial codes were examined, and trends, patterns and the most frequent and significant themes were identified.

There were frequent debriefing sessions between the first author doing the analysis and the other co-authors, during which themes were frequently discussed and revised. The meetings also provided a sounding board and opportunity for peer scrutiny. Moreover, a detailed account of the methods, procedures and decision points involved in carrying out this study was put 
together in the form of an 'audit trail', as advised by Shenton (2004). The assurance of analytic rigour to ensure that data was not selectively used and that the researcher's position did not overpower the participants' voices can be evidenced from the audit trails.

Key themes were determined after the discussion. This was followed by the theoretical coding, which connected the core categories to create the narrative proposition and theory of consumer behaviour on social media. The core variables were integrated and refined, including all core relationships: namely, existing consumer-brand, consumer-consumer, and prospective consumer-brand. These relationships were in turn related to one central concept: consumer behaviour on social media.

\section{Results}

The analysis of consumer behaviour in this context identified three key stakeholders and different relationships with unique behaviours. As presented in Figure 2 below, there is the existing consumer-brand relationship, the consumer-consumer relationship, and the prospective consumer-brand relationship. Examples of different tweets, which have been paraphrased for ethical reasons, are presented in Appendix 1 to illustrate these relationships.

------ Figure 2 about here -------

Existing consumer-brand relationship

These are interactions between consumers and the ES that provides their energy. These consumers often use social media to engage with their ES. 


\section{Making enquiries}

This seems to be one of the primary factors underpinning the consumer-brand relationship on social media. Consumers seem to see Twitter as an easier avenue to communicate with their energy provider when seeking advice about billing errors, arranging appointments, or finding out information about their tariffs. These tweets are often simple conversations with no argument or sense of urgency. In addition, some consumers tweet to ask for souvenirs from the companies, such as Wilbur the penguin (British Gas) or Zingy (EDF Energy) toys.

\section{Making complaints}

On a more serious note, consumers use Twitter to convey their anger and dissatisfaction with the service they have received or are receiving from their ES. These complaints often pertain to the time it takes to speak to someone on the phone. Moreover, when emails are not responded to, consumers log on to Twitter to complain and seek further assistance. Billing is another big issue, especially when consumers believe they are getting estimated bills despite having a smart meter (which is meant to automatically record meter readings and send them to the providers).

\section{Offering compliments}

On a positive note, some consumers take the time to show their appreciation of an ES for their timeliness in responding to their enquiries or for sending out an engineer to fix their problems, especially when they have vulnerable adults and children at home. Some individuals also offer positive word of mouth, suggesting that they are happy with their suppliers. Those consumers who have switched providers also take the time to publicly appreciate their new providers and highlight how they are saving money and that their accounts are being managed well. It is not known if these consumers would have taken the time to telephone the companies to share these positive experiences, as social media offers a faster and more public way of declaring their appreciation for the brands. 


\section{Consumer-consumer relationship}

Consumers often express their satisfaction and/or dissatisfaction on social media. A consumerconsumer relationship refers to consumers of certain providers sharing information about the benefits of their brands with consumers of the same or different providers.

\section{Looking out for each other}

Consumers tend to look out for themselves, but also advise each other about problems and issues with their ES. These issues could be security concerns (e.g. fraudulent people impersonating engineers), technical problems, or better deals or tariffs that other consumers can switch to. While this relationship is similar to those observed in brand communities on Facebook, due to the nature of Twitter, the responses are presented in the form of replies to tweets. Often the brand name is not @ mentioned, as these are community interactions in which providers are not necessarily involved.

\section{Recommending suppliers}

Consumers who are happy with their ES often recommend their provider to others. For example, these recommendations could take the form of replies to a tweet talking about how another provider is increasing their direct debit or putting consumers on more expensive tariffs. The replies offer alternatives and advise the author of the original tweet to switch so that they can get a better deal. The replies may also suggest comparison websites and share referral links where the new customer can have their bill reduced if they use the link. These referral links are often efforts by ES to build their customer base through recommendations from existing consumers. Those who use sustainable forms of energy also use the platform to tell other consumers about the reduction in $\mathrm{Co} 2$ gas emissions they can achieve if they switch providers. 


\section{Condemning suppliers}

Some consumers condemn their suppliers online and advise other people not to consider them. This sometimes happens when consumers of the same provider have a shared experience of bad service, especially billing problems, and engage in conversations that mention the name of the brand using the @ function. The consumers share their negative experiences and describe how they have been compelled to switch to another provider, advising other consumers to do likewise. There are also consumers who condemn energy brands because of their source of energy; these consumers ask other consumers to consider providers who utilise more sustainable energy sources in order to protect the environment.

Prospective consumer-brand relationship

Although this relationship is not as obvious or as strong as the previous two relationships, it offers providers the opportunity to build relationships with other consumers and present themselves in a better light.

\section{Reinforcing the conversation}

This occurs when prospective consumers join a conversation about an energy provider with the aim of reinforcing the comments of the existing consumers. The reinforcement is often drawn from their own experience and takes the form of either further appreciating what the ES has done or further amplifying the negative experience within their own network. This is how certain conversations can 'go viral', in that they extend outside the reach of the ES being tweeted about.

\section{Enquiring}

This often follows on from reinforcement if the experience has been positive. If the conversation is going well, the prospective customer engages in further conversation with the brand to find out more about its offers and to determine the differences between the brand and 
the customer's current provider. Other users then share links to information about switching providers, highlighting prices, customer services, and sustainable sources of energy as a means of competing with the bigger brands.

\section{Displaying behaviours}

The features of social media have changed the ways in which individuals interact with brands. Consumers therefore often display certain behaviours as they engage with the brands and other consumers. Consumers can share images to buttress their engagement with the brands, share links that other consumers may find relevant, or even report poor customer experiences to external stakeholders and regulators. This section presents some consumer behaviours associated with engaging with brands on social media.

\section{Graphical presentation}

Consumers present their concerns in graphical form by sharing images and emojis in their tweets. For example, to express their frustration with having to wait to speak to a customer adviser on the phone, some consumers shared images of their phone screen with various waiting times, while others shared images of their bills when disputing bills sent by the provider, or screenshots of emails informing them of an increase to their direct debit. On a more positive note, some consumers also shared images of free items they have received from the ES and pictures of corporate social responsibility activities engaged in by the providers.

\section{Mentioning the provider}

To ensure that the ES sees their tweets, consumers put the ES's Twitter handle in their conversation, preceded by the @ symbol. However, sometimes an incorrect handle is used by mistake. For example, the official and verified handle of Npower's customer service is @ npowerhelp, but there are similar handles, such as @ npower_ng (the Nigerian government's empowerment initiative). 


\section{Ignoring the provider}

There are also conversations in which the provider's handle is omitted from the tweet because the @ symbol is not included. This could be done either because the consumers do not want the provider to see the tweets (because they are engaging with fellow consumers) or because they simply cannot be bothered to include the ES's handle. It is unsurprising that the providers' social media managers will often pick these conversations up and attempt to engage, but consumers may not be willing to discuss the matter further. The parties may then continue the conversation via direct messaging.

\section{Asking for a follow-back}

As some questions cannot be solved through tweets in the public domain, the brand may often ask the consumers to send their details as a direct message. In some cases, users on Twitter cannot exchange direct messages if they are not following each other, which often necessitates requesting a follow-back. However, some providers have set their direct message inbox to be open to prevent the need for follow-backs.

\section{Sharing links}

When looking out for each other and recommending relevant services, consumers also share links among themselves. These could be intended either to recommend a different provider, to share a referral link, or to provide relevant information to assist others (such as links to comparison websites and other providers offering better deals).

\section{Comparison}

Consumers also compare individual ES to other ES in their tweets. They highlight the benefits of a specific provider and show other consumers how they can save money if they switch providers. When consumers are discussing their switching experiences, they sometimes mention their old providers and contrast them with their new providers and the benefits they 
offer (e.g. that bills are dealt with properly, that they use sustainable energy, that they have a better phone application, or that they have outstanding customer service).

\section{Making a report}

Some consumers feel that their ongoing issues with their provider are not being resolved quickly enough. Therefore, they make a report simply by using @ and including the ES's username in the conversation. There is also evidence of consumers reporting their ES to the government department responsible for the energy sector (the Department for Environment Food \& Rural Affairs), the regulator (Ofgem), and consumer bodies (Citizens Advice and Money Saving Expert) to complain about the poor service they have received, especially when switching, or because they feel their concerns are not being addressed.

\section{DISCUSSION AND CONCLUSION}

This study presents the results of the sentiment and thematic analyses of tweets to help facilitate an understanding of consumer-brand relations on social media with a focus on the UK energy sector. Social capital theory, which recognises the potential resources embedded within a network of relationships (Nahapiet \& Ghoshal, 1998), was adopted to understand the consumer behaviour of UK energy provider consumers on social media. Consumers were observed to use their social capital to help other consumers, engage with brands, form relationships, and build networks of support. Although Twitter does not have identified community groups, there is evidence of information and resource sharing between consumers with shared goals.

Sentiment analysis of the extracted tweets was conducted to quantitatively understand how consumers engage on Twitter, while a thematic analysis of the tweets qualitatively explored the different relationships and inherent behaviours. This both extends and differs from the study by Mogaji et al. (2018) that used user-generated content on the Facebook pages of UK energy companies. Firstly, a larger sample of user-generated comments was used and obtained from 
Twitter. Secondly, the present study extends beyond the 'Big Six' energy suppliers to uncover sentiments and forms of engagement with other suppliers in the sector. Thirdly, a thematic analysis was also conducted to determine the factors shaping consumers' behaviour as they engage on social media.

The results indicated that consumers do engage with ES, but that the low level of engagement with small, independent and white label suppliers is concerning. The BSES are shaping the conversation around energy provision, which highlights a gap in the understanding of the consumers of other brands. It is possible that these consumers may not be willing to use social media to offer compliments or make complaints, or that there are not enough consumers to drive the conversation; moreover, in the case of WLES, it is possible that the consumers do not know who to engage with. These inherent behaviours are worth investigating further, as the social ties and benefits within the social network are not being explored to their fullest extent at present. As Nahapiet and Ghosha (1998) noted, these ties may alert the organisation to opportunities for greater engagement with consumers and improvement of their customer experience. At time of writing, however, these brands are not gaining additional insight into their consumers, and the consumers are not making their concerns known.

Capturing consumer feelings through online brand engagement is considered a key element of monitoring social media (Cvijikj \& Michahelles, 2011). Three key relationships between brands and consumers have been identified, along with their inherent behaviours, which can shape how brands develop their marketing campaigns. This aligns with previous findings that users use social media to gather information and for social interaction (Stafford, et al., 2004). In addition, consumers' willingness to post pictures and mention other consumers in their tweets offers opportunities for brands to engage and increase their exposure and visibility (Saravanakumar \& SuganthaLakshmi, 2012). 
As noted above, $40.5 \%$ of the total tweets represent the BSES. Relatively speaking, these suppliers had higher negative reviews compared to the other energy provider groups. This is mainly because of the high engagement that BSES receive from both present and prospective consumers. In terms of future growth, building sustainable relationships is crucial for any sector (Stevens et al., 2016). This is especially true in the energy sector, since it is necessary to deal with both industrial and day-to-day end consumers. The more the width of the customer segment increases, the more the companies are required to handle different customer segments with different socio-demographic profiles (Tsimonis and Dimitriadis, 2014; Farinloye et al., 2019). This consequently puts pressure on the companies to handle consumers in the social media domain. White label companies exhibited sentiments similar to those of the BSES companies.

Renewable energy suppliers exhibited high positive sentiments compared to the other three energy groups. This is mainly because of their consistent services as perceived by consumers. The remaining groups, including BSES, could follow a similar social media strategy to garner positive sentiments in their tweets. Previous studies have supported the conclusion that attracting positive sentiments is crucial to building sustainable brands and organisational value (Smith et al., 2012). Accordingly, the results of Study 1 allow the energy sector groups to be benchmarked against each other.

From a theoretical perspective, this paper makes four key contributions. First, it extends knowledge of consumer behaviour on social media, especially regarding the UK energy sector, by conceptualising the core relationships between brands and consumers and the consumer behaviour inherent to social media, highlighting the evolving and dynamic nature of service experience and brand engagement, which is enhanced by interaction and relational activities. It is anticipated that the postulated theory will further stimulate research into online consumer behaviour across different sectors. 
Second, the study extends the application of social capital theory to include brand conversations on Twitter, highlighting its community-related possibilities and offering a contemporary, essential, and interconnected understanding of consumer behaviour online with a focus on the energy sector. It has demonstrated the importance of energy in the UK and how consumers are eager to share their concerns online in the hope of obtaining a speedy response. Third, while acknowledging the unique and dynamic nature of consumer behaviour on social media (Alalwan, et al., 2017), the present study has looked beyond capturing consumer behaviour on social networks and web-based online tools for marketing and product distribution, with the aim of providing a theoretical understanding of consumer behaviour on Twitter.

Fourth, methodologically speaking, this study contributes towards literature on sentiment analysis and social media research (Aswani, et al., 2018). The approach offers an effective means of data collection and analysis that differs from conventional interviews or surveys. This study further provides insight into consumer sentiments and natural behaviour in the social media environment using the artificial intelligence, NLP and big data methods that are emerging in management research. For example, a simple search for a service provider on Twitter may yield a greater number of negative tweets, because the algorithms highlight tweets with a higher number of replies, retweets, or favourites (Mogaji \& Erkan, 2019); however, sentiment analysis is able to explore on a deeper level that goes beyond the superficial in order to provide insight into positive tweets that may not have received a lot of engagement. Human analysis of these tweets (as was conducted in Study 2) may be necessary to gain a better understanding of these sentiments in context. In addition, the study focuses on consumers' willingness to share their comments and display their behaviours publicly; this increased the credibility of the data and provided reliable insights into consumer attitudes towards the brand. 
This may not always be the case when consumers are interviewed or asked to fill out questionnaires about their online behaviours.

The current study offers implications for consumers as well, since they use social media to engage with brands. It is acknowledged that consumers will use social media to share relevant information with their network and request additional information. This is illustrated by consumers sharing personalised links to encourage other consumers to switch their energy providers. In their own small way, these consumers feel like influencers, encouraging other consumers to make a better choice of provider. This highlights an implication for brands regarding how they can best engage with their consumers in other to bring other consumers on board: in short, a form of electronic word of mouth.

Secondly, consumers need to be reassured that an ES will make an effort to respond to enquiries on social media. However, the consumers must also recognise that a timely response (or any response at all) cannot always be guaranteed, as the ES may be dealing with many other enquiries as well. For example, in the case of an emergency such as a gas leak or power cut, social media may not always be the best means of communication, as social media managers may miss some crucial tweets as they deal with numerous enquiries.

From a managerial perspective, moreover, the current study offers implications that highlight the need for managers of energy suppliers in the UK to encourage consumers to engage on social media; this is particularly true for consumers of providers outside of the Big Six. Overall, all energy suppliers in the UK should take social media environments like Twitter seriously as an important channel for customer services such as handling customer queries or complaints. This suggests the need for brands to improve their manpower and resources in order to deal with these growing demands. This could mean having more staff available to respond to tweets, using artificial intelligence and chatbots to respond to frequently asked questions, or using 
software and tools to aid the communication process (Dwivedi, et al., 2019). In addition, brands needs to make their online availability known to consumers. For example, @BritishGasHelp disclosed that they are available 8am-10pm Monday to Friday and 8am-6pm Saturday and Sunday, while @edfenergycs is only available 8am-8pm Monday to Friday and not on weekends.

Secondly, managers need to take proactive action to monitor topics that can generate positive sentiments and create messages and content promoting those topics accordingly. As for BSES, although their mentions are currently dominant in the Twitter environment, the high proportion of negative reviews serve as an alarming signal that these suppliers should make efforts to neutralise these sentiments and reviews by responding considerately to negative reviews and generating positive topics, or encouraging the sharing of positive reviews. Staff should be trained to respond promptly and effectively to messages sent to brands on social media. Consumer expectations are very high and they expect rapid answers; staff should respond professionally and be able to manage the situation effectively. In addition, any compliments should be shared and the staff members responsible should be informed (for example, if a customer tweets to express satisfaction with an engineer who came to repair the boiler).

Thirdly, engagement is very important, as highlighted by consumer behaviour on social media. Particularly for independent and small suppliers, managers need to consider approaches to motivate existing consumers to generate word-of-mouth and recommend their brands to other prospective consumers. Providers need to engage more on social media and understand what consumers are saying about their brands, as they may be missing out on the positive electronic word-of-mouth (Gökerik, et al., 2018) being shared by their consumers. For example, the user @PowershopUK joined Twitter in October 2012, and as of October 2018 had only published 250 tweets; this is an indication of their low level of engagement with consumers. 
Fourthly, brands should have an engaging presence on social media, and their accounts should be made available to assist consumers. Mogaji and Erkan (2019) found that some train companies have parody Twitter accounts, which can confuse consumers into thinking they are communicating with the right brand; this is another reason for brands to take charge of their communication strategies and make efforts to get verified and use names that consumers will easily recognise. For brands with many accounts, they need to refer consumers to the places where they can get help with their customer queries.

Lastly, engagement should go beyond simply responding to queries and complaints; brands should endeavour to engage in order to build relationships. This has an implication for content creation and marketing. Brands should share tweets that can inform and entertain, as well as meet the social needs of their consumers, as these are what Heinonen (2011) identified as the three main gratifications for consumers using the internet.

The positive sentiments and reviews expressed towards renewable energy suppliers also imply that policy makers may also need to develop a communication strategy for social media platforms such as Twitter to encourage consumers to consider renewable energy. In general, not only for the UK energy sector but also for any competitive markets in which Twitter is available and popular, marketers need to devise a communication and customer services strategy that incorporates Twitter.

There are, however, some limitations to this study. First, the demographics of the consumers whose tweets were analysed were not extracted, although it can be assumed that they are UK residents who get their energy from these suppliers. Second, as with any automated process, sentiment analysis is prone to error and often requires human eyes to check for issues. Thirdly, the same number of tweets was extracted from the $52 \mathrm{ES}$ for the thematic analysis; though this has been adopted by previous studies (Mogaji \& Erkan, 2019), a proportional number of tweets 
for each ES could also be considered. Finally, the study restricted itself to the analysis of tweets about suppliers in the UK energy sector, meaning that these results cannot be generalised to other sectors; however, this work has offered insights into key behaviours and relationships (albeit quantitative ones) that can be explored further. Future research should aim to analyse consumers in other sectors and countries to gain better insight into consumer behaviour on social media.

\section{References}

Alalwan, A. A., Rana, N. P., Dwivedi, Y. K. \& Algharabat, R., 2017. Social media in marketing: A review and analysis of the existing literature. Telematics and Informatics, 34(7), pp. 1177-1190.

Andéhn, M., Kazeminia, A., Lucarelli, A. \& Sevin, E., 2014. User-generated place brand equity on Twitter: The dynamics of brand associations in social media. Place branding and public diplomacy, 10(2), pp. 132-144.

Andrews, D., 2002. Audience-specific online community design. Communications of the ACM, 45(4), pp. 64-68.

Aswani, R., Kar, A. K., Ilavarasan, P. V. \& Dwivedi, Y. K., 2018. Search engine marketing is not all gold: insights from Twitter and SEOClerks. International Journal of Information Management, 38(1), pp. 107-116.

Bae, Y., \& Lee, H. (2012). Sentiment analysis of twitter audiences: Measuring the positive or negative influence of popular twitterers. Journal of the American Society for Information Science and Technology, 63(12), 2521-2535.

Balakrishnan, J. \& Griffiths, M. D., 2017. Social media addiction: What is the role of content in YouTube?. Journal of Behavioral Addictions, 6(3), pp. 364-377. 
Balakrishnan, J. \& Manickavasagam, J., 2016. User Disposition and Attitude towards Advertisements Placed in Facebook, LinkedIn, Twitter and YouTube: A Decision Tree and MANOVA Approach. Journal of Electronic Commerce in Organizations, 14(3), pp. 17-34.

Bermingham, A., \& Smeaton, A. F. (2010, October). Classifying sentiment in microblogs: is brevity an advantage?. In Proceedings of the 19th ACM international conference on Information and knowledge management (pp. 1833-1836). ACM.

Blanchard, A. L. \& Markus, M. L., 2004. The experienced sense of a virtual community: Characteristics and processes. ACM SIGMIS Database: the DATABASE for Advances in Information Systems, 35(1), pp. 64-79.

Blau, P. M., 2017. Exchange and Power in Social Life. 2nd ed. New York, NY, USA: Routledge.

Braun, V. \& Clarke, V., 2006. Using thematic analysis in psychology. Qualitative Research in Psychology, 3(2), pp. 77-101.

Bruhn, M., Schoenmueller, V. \& Schäfer, D. B., 2012. Are social media replacing traditional media in terms of brand equity creation?. Management Research Review, 35(9), pp. 770-790.

Chai, S. \& Kim, M., 2010. What makes bloggers share knowledge? An investigation on the role of trust. International Journal of Information Management, 30(5), pp. 408-415.

Chang, H. H. \& Chuang, S. S., 2011. Social capital and individual motivations on knowledge sharing: Participant involvement as a moderator. Information \& Management, 48(1), pp. 9-18.

Chiu, C. M., Hsu, M. H. \& Wang, E. T., 2006. Understanding knowledge sharing in virtual communities: An integration of social capital and social cognitive theories. Decision Support Systems, 42(3), pp. 1872-1888. 
Chowdhary, N. \& Prakash, M., 2007. Prioritizing service quality dimensions. Managing Service Quality: An International Journal, 17(5), pp. 493-509.

Chu, S., 2011. Viral advertising in social media. Journal of Interactive Advertising, 12(1), pp. $30-43$.

Coyne, B., 2017. Rise of the local authority energy companies. [Online] Available at: $\quad$ https://theenergyst.com/rise-of-the-local-authority-energy-companies/ [Accessed 1212 2018].

Cvijikj, I. P. \& Michahelles, F., 2011. A case study of the effects of moderator posts within a facebook brand page. Berlin, Heidelberg, Springer, pp. 161-170.

Dwivedi, Y. K. et al., 2019. Artificial Intelligence (AI): Multidisciplinary perspectives on emerging challenges, opportunities, and agenda for research, practice and policy. International Journal of Information Management. https://doi.org/10.1016/j.ijinfomgt.2019.08.002

Dwivedi, Y. K., Kapoor, K. K. \& Chen, H., 2015. Social Media Marketing and Advertising. The Marketing Review, 15(3), pp. 289-309.

Einwiller, S. A. \& Steilen, S., 2015. Handling complaints on social network sites-An analysis of complaints and complaint responses on Facebook and Twitter pages of large US companies. Public Relations Review, 41(2), pp. 195-204.

Energy UK, 2018. Energy in the UK, London: Energy UK.

Farinloye, T. \& Mogaji, E., 2018. A Typology of UK Energy Service Brands based on Size, Licencing and Source of Energy. Questbury Brand Series, Volume 2019, pp. 70-78. http://dx.doi.org/10.2139/ssrn.3413443 
Farinloye, T., Wayne, T., Mogaji, E., \& Kuika Watat, J. (2019). Social media for universities' strategic communication. In: Strategic Marketing of Higher Education in Africa. (96-115). Oxfordshire: Routledge. https://doi.org/10.4324/9780429320934-8

Ghiassi, M., Skinner, J. \& Zimbra, D., 2013. Twitter brand sentiment analysis: A hybrid system using n-gram analysis and dynamic artificial neural network. Expert Systems with applications, 40(16), pp. 6266-6282.

Giovanis, A., 2016. Consumer-brand relationships' development in the mobile internet market: evidence from an extended relationship commitment paradigm. Journal of Product and Brand Management, 25(6), pp. 568-585.

Goh, K. Y., Heng, C. S. \& Lin, Z., 2013. Social media brand community and consumer behavior: Quantifying the relative impact of user-and marketer-generated content.. Information Systems Research, 24(1), pp. 88-107.

Gökerik, M. et al., 2018. Surprise me with your ads! The impacts of guerrilla marketing in social media on brand image. Asia Pacific Journal of Marketing and Logistics, 30(5), pp. 12221238.

Goodman, R., 2018. Record numbers of energy customers shun the Big Six by switching to smaller suppliers.

[Online]

Available at: https://www.thisismoney.co.uk/money/bills/article-5950923/Record-numbers$\underline{\text { energy-customers-shun-Big-Six-switching-smaller-suppliers.html }}$ [Accessed 1212 2018].

Hau, Y. S. \& Kim, Y. G., 2011. Why would online gamers share their innovation-conducive knowledge in the online game user community? Integrating individual motivations and social capital perspectives. Computers in Human Behavior, 27(2), pp. 956-970. 
Hayes, J. L. \& King, K. W., 2014. The social exchange of viral ads: Referral and coreferral of ads among college students. Journal of Interactive Advertising, 14(2), pp. 98-109.

Heinonen, K., 2011. Consumer activity in social media: Managerial approaches to consumers' social media behavior. Journal of Consumer Behavior, 10(6), pp. 356-364.

Heller Baird, C. \& Parasnis, G., 2011. From social media to social customer relationship management. Strategy \& Leadership, 39(5), pp. 30-37.

Hernon, P. \& Nitecki, D. A., 2001. Service quality: A concept not fully explored. Library Trends, 49(4), pp. 687-708.

HM Government, 2018. A Green Future: Our 25 Year Plan to Improve the Environment, London: Department for Environment, Food \& Rural Affairs.

Ibrahim, N. F., Wang, X. \& Bourne, H., 2017. Exploring the effect of user engagement in online brand communities: Evidence from Twitter. Computers in Human Behavior, Volume 72, pp. 321-338.

Kapoor, K. K. et al., 2018. Advances in social media research: past, present and future. Information Systems Frontiers, 20(3), pp. 531-558.

Katz, E., Gurevitch, M. \& Haas, H., 1973. On the Use of the Mass Media for Important Things. American Sociological Review, 38(2), p. 164-81.

Kozinets, R. V., 2010. Netnography: Doing ethnographic research online. Sage publications. Thousand Oaks: Sage.

Kozinets, R. V., 2015. Netnography. London: John Wiley. 
Kozinets, R. V., Dolbec, P. Y. \& Earley, A., 2014. Netnographic analysis: Understanding culture through social media data. In: The SAGE handbook of qualitative data analysis. s.l.:s.n., pp. 262-276.

Li, J. \& Hovy, E., 2017. Reflections on sentiment/opinion analysis. In: A Practical Guide to Sentiment Analysis. Cham: Springer, pp. 41-59.

Lovejoy, K. \& Saxton, G. D., 2012. Information, community, and action: How nonprofit organizations use social media. Journal of Computer-Mediated Communication, 17(3), pp. 337-353.

Makarem, S. C. \& Jae, H., 2016. Consumer boycott behavior: An exploratory analysis of twitter feeds. Journal of Consumer Affairs, 50(1), pp. 193-223.

Marwick, A. E. \& Boyd, D., 2011. I tweet honestly, I tweet passionately: Twitter users, context collapse, and the imagined audience. New media \& society, 13(1), pp. 114-133.

McCormick, M., 2018. One Select joins growing list of failed UK energy suppliers. [Online] Available at: $\quad$ https://www.ft.com/content/7a1d697e-fc67-11e8-aebf-99e208d3e521 [Accessed 1212 2018].

Mogaji, E. \& Erkan, I., 2019. Insight into consumer experience on UK train transportation services. Travel Behaviour and Society, Volume 14, pp. 21-33.

Mogaji, E. \& Farinloye, T., 2017. Attitudes towards brands and advertisements: qualitative and thematic analysis of social media data. In: B. Rishi \& S. Bandyopadhyay, eds. Contemporary Issues in Social Media Marketing. London: Routledge., pp. 206-216.

Mogaji, E., Farinloye, T. \& Aririguzoh, S., 2016. Factors shaping attitudes towards UK bank brands: An exploratory analysis of social media data. Cogent Business \& Management, 3(1), p. 1223389. 
Mogaji, E., Ukpabi, D. \& Olaleye, S., 2018. Examining Consumer-Brand Relationships in the UK Energy Sector: A Social Media Perspective. Stirling, Scotland, Academy of Marketing.

Mueller, G., n.d. Why Twitter is the Ideal Platform for Engagement. [Online] Available at: $\quad$ https://www.convinceandconvert.com/social-media-strategy/twitterengagement/

[Accessed 22 2019].

Nahapiet, J. \& Ghoshal, S., 1998. Social capital, intellectual capital, and the organizational advantage. The Academy of Management Review, 23(2), p. 242-266.

Natarajan, T., Balakrishnan, J., Balasubramanian, S. A. \& Manickavasagam, J., 2014. Perception of Indian consumers towards social media advertisements in Facebook, LinkedIn, YouTube and Twitter. International Journal of Internet Marketing and Advertising, 8(4), pp. 264-284.

Ngai, E. W., Tao, S. S. \& Moon, K. K., 2015. Social media research: Theories, constructs, and conceptual frameworks. International Journal of Information Management, 35(1), pp. 33-44.

Ofgem, 2014. White Label providers - Consultation. [Online] Available at: https://www.ofgem.gov.uk/publications-and-updates/white-label-providers$\underline{\text { consultation }}$

[Accessed 116 2019].

Ofgem, 2018. Default tariff price cap level: 1 January 2019 to 31 March 2019. [Online] Available at: https://www.ofgem.gov.uk/publications-and-updates/default-tariff-price-cap$\underline{\text { level-1-january-2019-31-march-2019 }}$

[Accessed 1212 2018]. 
Ofgem, 2018. Retail Market Indicators. [Online]

Available at: $\quad$ https://www.ofgem.gov.uk/data-portal/retail-market-indicators

[Accessed 1212 2018].

Ofgem, 2019. Number of active domestic suppliers by fuel type (GB). [Online] Available at: Number of active domestic suppliers by fuel type (GB) [Accessed 315 2019].

Parmar, B., 2015. 50 companies that get twitter - and 50 that don't. [Online] Available at: $\quad$ https://hbr.org/2015/ 04/the-best-and-worst-corporate-tweeters [Accessed 22 2019].

Patton, M. Q., 1990. Qualitative evaluation and research methods. 2nd ed. Newbury Park, CA: Sage.

Pentina, I., Guilloux, V. \& Micu, A. C., 2018. Exploring Social Media Engagement Behaviors in the Context of Luxury Brands. Journal of Advertising, 47(1), pp. 55-69.

Philander, K., \& Zhong, Y. (2016). Twitter sentiment analysis: Capturing sentiment from integrated resort tweets. International Journal of Hospitality Management, 55(2016), 16-24.

Roberts, K. et al., 2012. EmpaTweet: Annotating and Detecting Emotions on Twitter. Istanbul, Turkey, European Language Resources Association (ELRA), pp. 3806-3813.

Ruggeri, A. \& Samoggia, A., 2018. Twitter communication of agri-food chain actors on palm oil environmental, socio-economic, and health sustainability. Journal of Consumer Behaviour, 17(1), pp. 75-93.

Sabrina, T. H. \& Shobeiri, S., 2016. The relative impacts of experiential and transformational benefits on consumer-brand relationship. Journal of Product \& Brand Management, 25(6), pp. 586-599. 
Saleem, A. et al., 2014. Pre-processing methods of data mining. London, IEEE/ACM 7th International Conference, pp. 451-456.

Saravanakumar, M. \& SuganthaLakshmi, T., 2012. Social media marketing. Life Science Journal, 9(4), pp. 4444-4451.

Schivinski, B. \& Dabrowski, D., 2015. The impact of brand communication on brand equity through Facebook. Journal of Research in Interactive Marketing, 9(1), pp. 31-53.

Shareef, M. A., Dwivedi, Y. K. \& Kumar, V., 2016. Exploring multichannel: strategy and consumer behavior. The Marketing Review, 16(3), pp. 235-263.

Shenton, A. K., 2004. Strategies for ensuring trustworthiness in qualitative research projects. Education for information, 22(2), pp. 63-75.

Smith, A. N., Fischer, E. \& Yongjian, C., 2012. How does brand-related user-generated content differ across YouTube, Facebook, and Twitter?. Journal of Interactive Marketing, 26(2), pp. 102-113.

Stevens, T. M., Aarts, N., Termeer, C. J. \& Dewulf, A., 2016. Social media as a new playing field for the governance of agro-food sustainability.. Current Opinion in Environmental Sustainability, Volume 18, pp. 99-106.

Stieglitz, S. \& Dang-Xuan, L., 2013. Emotions and information diffusion in social mediasentiment of microblogs and sharing behavior. Journal of management information systems, 29(4), pp. 217-248.

Strauss, A. \& Corbin, J., 1990. Basics of qualitative research: Grounded theory procedures and techniques. London: Sage.

Susarla, A., Oh, J. H. \& Tan, Y., 2012. Social networks and the diffusion of user-generated content: Evidence from YouTube. Information Systems Research, 23(1), pp. 23-41. 
Textblob,

2019.

Tutorial:

Quickstart.

[Online]

Available

at:

https://textblob.readthedocs.io/en/dev/quickstart.html

[Accessed 112 2019].

Thelwall, M., Buckley, K., \& Paltoglou, G. (2011). Sentiment in Twitter events. Journal of the American Society for Information Science and Technology, 62(2), 406-418.

Tsai, W. H. \& Men, L. R., 2013. Motivations and antecedents of consumer engagement with brand pages on social networking sites. Journal of Interactive Advertising, 13(2), pp. 76-87.

Tsimonis, G. \& Dimitriadis, S., 2014. Brand strategies in social media. Marketing Intelligence \& Planning, 32(3), pp. 328-344.

Ukpabi, D., Karjaluoto, H., Olaleye, S., \& Mogaji, E. (2019). Influence of Offline Activities and Customer Value Creation on Online Travel Community Continuance Usage Intention. In Information and Communication Technologies in Tourism (pp. 450-460). Cham: Springer.

Valos, M. J., Maplestone, V. L., Polonsky, M. J. \& Ewing, M., 2017. Integrating social media within an integrated marketing communication decision-making framework. Journal of Marketing Management, 33(17-18), pp. 1522-1558.

Walasek, L., Bhatia, S. \& Brown, G. D., 2018. Positional goods and the social rank hypothesis: Income inequality affects online chatter about high-and low-status brands on Twitter. Journal of Consumer Psychology, 28(1), pp. 138-148.

Walker, L., Baines, P. R., Dimitriu, R. \& Macdonald, E. K., 2017. Antecedents of retweeting in a (political) marketing context. Psychology \& Marketing, 34(3), pp. 275-293.

Xiang, Z. \& Gretzel, U., 2010. Role of social media in online travel information search. Tourism Management, 31(2), pp. 179-188. 
Ukpabi, D., Karjaluoto, H., Olaleye, S., \& Mogaji, E. (2019). Influence of Offline Activities and Customer Value Creation on Online Travel Community Continuance Usage Intention. In Information and Communication Technologies in Tourism (pp. 450-460). Cham: Springer. 